\title{
Heteroatom Tuning of Bimolecular Criegee Reactions and Its Implications
}

\author{
Manoj Kumar and Joseph S. Francisco*
}

\begin{abstract}
High-level quantum-chemical calculations have been performed to understand the key reactivity determinants of bimolecular reactions of Criegee intermediates and $\mathrm{H}_{2} \mathrm{X}$ $(X=O, S, S e$, and $T e)$. Criegee intermediates are implicated as key intermediates in atmospheric, synthetic organic, and enzymatic chemistry. Generally, it is believed that the nature and location of substituents at the carbon of the Criegee intermediate play a key role in determing the reactivity. However, the present work suggests that it is not only the substitution of the Criegee intermediate, but the nature of the heteroatom in $\mathrm{H}_{2} \mathrm{X}$ that also plays a crucial role in determining the reactivity of the interaction between the Criegee intermediate and $\mathrm{H}_{2} \mathrm{X}$. The barriers for the reactions of Criegee intermediates and $\mathrm{H}_{2} \mathrm{X}$ satisfy an inverse correlation with the bond strength of $\mathrm{X}-\mathrm{H}$ in $\mathrm{H}_{2} \mathrm{X}$, and a direct correlation with the first $\mathrm{pK}_{a}$ of $\mathrm{H}_{2} \mathrm{X}$. This heteroatom tuning causes a substantial barrier lowering of 8-11 kcalmol $\mathrm{kn}^{-1}$ in the Criegee reaction barrier in going from $\mathrm{H}_{2} \mathrm{O}$ to $\mathrm{H}_{2} \mathrm{Te}$. An important implication of these results is that the reaction of the Criegee intermediate and $\mathrm{H}_{2} \mathrm{~S}$ could be a source of thioaldehydes, which are important in plantery atmospheres and synthetic organic chemistry. By performing the reaction of Criegee intermediates and $\mathrm{H}_{2} \mathrm{~S}$ under water or acid catalysis, thioladehydes could be detected in a hydrogen-bonded complexed state, which is significantly more stable than their uncomplexed form. As a result, simpler aliphatic thioaldehydes could be selectively synthesized in the laboratory, which, otherwise, has been a significant synthetic challenge because of their ability to oligomerize.
\end{abstract}

$U_{n}$ derstanding reaction chemistry of Criegee intermediates has become a hot topic of research in the recent past. Criegee intermediates are carbonyl oxides that are principally produced in the ozone-olefin cycloaddtions. ${ }^{[1]}$ The unimolecular and bimolecular Criegee reactions play a crucial role in the tropospheric budgets of hydroxy radicals, organic acids, hydroperoxides, nitrates, sulfates and secondary organic aerosols. ${ }^{[2-9]}$ At the same time, Criegee chemistry is a key component of ozonolysis-based syntheses that offer safe and scalable routes for synthesizing pharmaceutical intermediates and other useful commodities. ${ }^{[10-12]}$ Criegee intermediates are also implicated in the reaction cycles of flavin-dependent

[*] Dr. M. Kumar, Prof. J. S. Francisco

Department of Chemistry, University of Nebraska-Lincoln Lincoln, NE 68588 (USA)

E-mail: jfrancisco3@unl.edu

(2) Supporting information for this article can be found under: http://dx.doi.org/10.1002/anie.201604848.
Baeyer-Villiger monooxygenases ${ }^{[13]}$ that provide an environmentally benign route for forming enantiopure drugs. ${ }^{[14]}$

Because of its broad profile, factors influencing the reactivity of Criegee intermediates have been extensively investigated by experimental and theoretical means. The nature and location of the substituents on the Criegee intermediate significantly tune its reactivity. ${ }^{[15]}$ Criegee intermediates having a methyl substituent in the anti position react faster than Criegee intermediates having a methyl substituent in syn position. Criegee intermediates with electron-withdrawing substituents and zwitterionic character react faster than those having electron-releasing substituents. Substitution in the Criegee intermediate can cause up to ten orders of magnitude differences in its reactivity. The unimolecular and bimolecular reactions of the Criegee intermediate $\mathrm{CH}_{3} \mathrm{CHOO}$ represent one of the well-studied conformerdependent Criegee reactivity profile.

Criegee intermediates participate in various bimolecular reactions. Though the effect of Criegee substitution in bimolecular reactions has been well explored, the effect of substituent in the non-Criegee reacting partner is less so. For example, the most probable bimolecular Criegee reaction in troposphere is the reaction with water. However, it is not clear whether the nature of heteroatom $\mathrm{X}$ in $\mathrm{H}_{2} \mathrm{X}(\mathrm{X}=\mathrm{O}, \mathrm{S}$, $\mathrm{Se}$, and $\mathrm{Te}$ ) would alter the energetics of the reaction of Criegee intermediates and $\mathrm{H}_{2} \mathrm{X}$. Does there exist any correlation between the Criegee reaction barrier and the heteroatom nature? If yes, what are its implications? If not, what other factors influence the reaction of Criegee intermediates and $\mathrm{H}_{2} \mathrm{X}$ ? A detailed knowledge of these determinants may provide general guidelines for synthesizing useful organic compounds, which are otherwise difficult to synthesize, and in addition, may also reveal new source of atmospherically important thioaldehydes, thus improving molecular details of existing atmospheric models.

Here it is shown using high-level quantum-chemical calculations that such a tuning of the barrier for the reaction of the Criegee intermediate and $\mathrm{H}_{2} \mathrm{X}$ is indeed possible and more importantly, this heteroatom tuning is also found to be a general trend among other atmospherically important reactions. Firstly, examining the gas-phase reaction between the simplest Criegee intermediate, $\mathrm{CH}_{2} \mathrm{OO}$, and $\mathrm{H}_{2} \mathrm{X}$; the reaction energetics are computed by performing single-point calculations using the coupled-cluster single and double substitution method with a perturbative treatment of triple excitations $(\mathrm{CCSD}(\mathrm{T}))$ and the augmented correlation-consistent triplet zeta basis set, aug-cc-pVTZ at the M06-2X/augcc-pVTZ optimized geometries. (See the Supporting Information for details.) The $\mathrm{CH}_{2} \mathrm{OO}-\mathrm{H}_{2} \mathrm{X}$ reaction is a multi-step reaction that converts the Criegee moiety, $-\mathrm{COO}$ into $-\mathrm{C}=\mathrm{X}$ 
functional group. The reaction consists of two main steps namely chalcogen hydride $\left(\mathrm{H}_{2} \mathrm{X}\right)$ addition and hydrogen peroxide $\left(\mathrm{H}_{2} \mathrm{O}_{2}\right)$ elimination with the latter step being its ratelimiting step (see Figure 1 and Table S1 in the Supporting Information). Overall, the reaction is at least $24.1 \mathrm{kcal} \mathrm{mol}^{-1}$

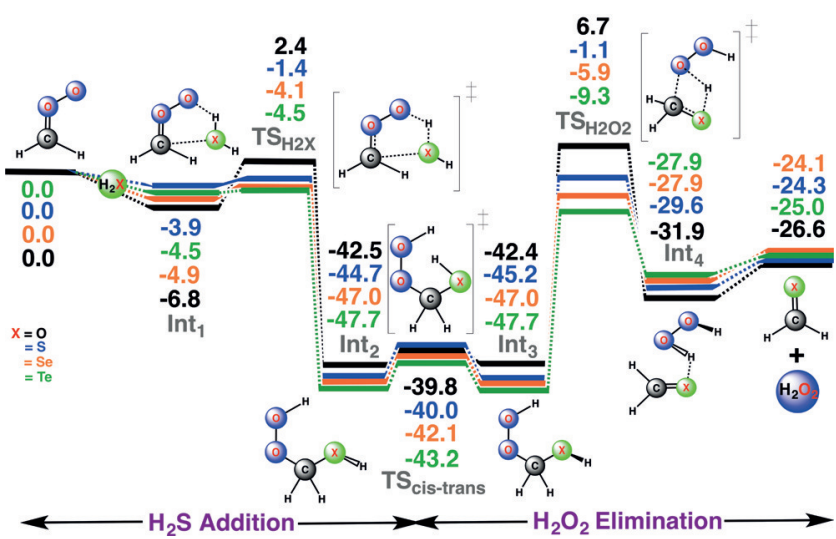

Figure 1. $C C S D(T) / a u g-c c-p V T Z / / M 06-2 X / a u g-c c-p V T Z$ calculated zeropoint-corrected reaction profiles for the reaction between the simplest Criegee intermediate, $\mathrm{CH}_{2} \mathrm{OO}$ and various chalcogen hydrides, $\mathrm{H}_{2} \mathrm{X}$ $(\mathrm{X}=\mathrm{O}, \mathrm{S}, \mathrm{Se}$, and $\mathrm{Te})$. The energies are given in $\mathrm{kcal} \mathrm{mol}^{-1}$ units.

exoergic. For the $\mathrm{CH}_{2} \mathrm{OO}-\mathrm{H}_{2} \mathrm{O}$ reaction, the addition step has a barrier of $9.2 \mathrm{kcalmol}^{-1}$ relative to $\mathbf{I n t}_{\mathbf{1}}$ whereas the elimination step has a barrier of $49.1 \mathrm{kcal} \mathrm{mol}^{-1}$ relative to Int $_{3}, \mathrm{H}_{2} \mathrm{C}(\mathrm{OH})(\mathrm{OOH})$. These barriers are signficantly reduced upon changing the heteroatom $\mathrm{X}$ in $\mathrm{H}_{2} \mathrm{X}$. For the $\mathrm{CH}_{2} \mathrm{OO}-\mathrm{H}_{2} \mathrm{~S}$ reaction, the addition barrier is just $2.5 \mathrm{kcal}$ $\mathrm{mol}^{-1}$ and the $\mathrm{H}_{2} \mathrm{O}_{2}$ elimination barrier is $44.1 \mathrm{kcal} \mathrm{mol}^{-1}$. For the $\mathrm{H}_{2} \mathrm{Se}$ and $\mathrm{H}_{2} \mathrm{Te}$ reactions, the addition steps involve barriers smaller than $1.0 \mathrm{kcalmol}^{-1}$ whereas the barriers for the elimination step are lowered to 41.1 and $38.4 \mathrm{kcal} \mathrm{mol}^{-1}$, respectively. It is important to mention here that the hydroperoxide in the addition step ( $\mathbf{I n t}_{\mathbf{2}}$ or $\mathbf{I n t} \mathbf{H}_{\mathbf{3}}$ ) is formed with an excess energy of at least $42.2 \mathrm{kcalmol}^{-1}$ that significantly compensates the high barrier for the elimination step. These results clearly suggest that there is a correlation between the Criegee reaction barrier and the nature of $\mathrm{X}$ in $\mathrm{H}_{2} \mathrm{X}$. This correlation can be explained in terms of the $\mathrm{H}-\mathrm{X}$ bond length or atomic radius of $\mathrm{X}$ (Figure 2). Moving down the chalcogen group, the atomic radius increases and the $\mathrm{H}-\mathrm{X}$ bond becomes weaker. Since the $\mathrm{H}_{2} \mathrm{X}$ addition to the Criegee intermediate involves breakage of one of the $\mathrm{H}-\mathrm{X}$ bonds, a weaker $\mathrm{H}-\mathrm{X}$ bond in $\mathrm{H}_{2} \mathrm{X}$ would promote the $\mathrm{H}_{2} \mathrm{X}$ addtion across the Criegee moiety. The oxygen atom has the shortest atomic radius of $66 \mathrm{pm}$, and the $\mathrm{O}-\mathrm{H}$ bond $(96 \mathrm{pm})$ with an enthalpy of $463 \mathrm{~kJ} \mathrm{~mol}^{-1}$ is the strongest $\mathrm{X}-\mathrm{H}$ bond whereas Te atom has the largest radius $(138 \mathrm{pm})$, and the $\mathrm{Te}-\mathrm{H}$ bond $(169 \mathrm{pm})$ with an enthalpy of $267 \mathrm{~kJ} \mathrm{~mol}^{-1}$ is the weakest $\mathrm{X}-\mathrm{H}$ bond. ${ }^{[16]}$ This explains why the $\mathrm{H}_{2} \mathrm{O}$ reaction has the largest barriers whereas the $\mathrm{H}_{2}$ Te reaction has the lowest ones. The barriers for the $\mathrm{H}_{2} \mathrm{X}$ reactions also directly correlate with first $\mathrm{p} K_{\mathrm{a}}$ value of $\mathrm{H}_{2} \mathrm{X}$ (Figure $\mathrm{S} 1$ ). $\mathrm{H}_{2} \mathrm{O}$ has the largest $\mathrm{p} K_{\mathrm{a}}$ value of 15.7 where $\mathrm{H}_{2} \mathrm{Te}$ has the lowest $\mathrm{p} K_{\mathrm{a}}$ value of 3.0, which is consistent with the barrier trends. ${ }^{[17]}$ This implies that
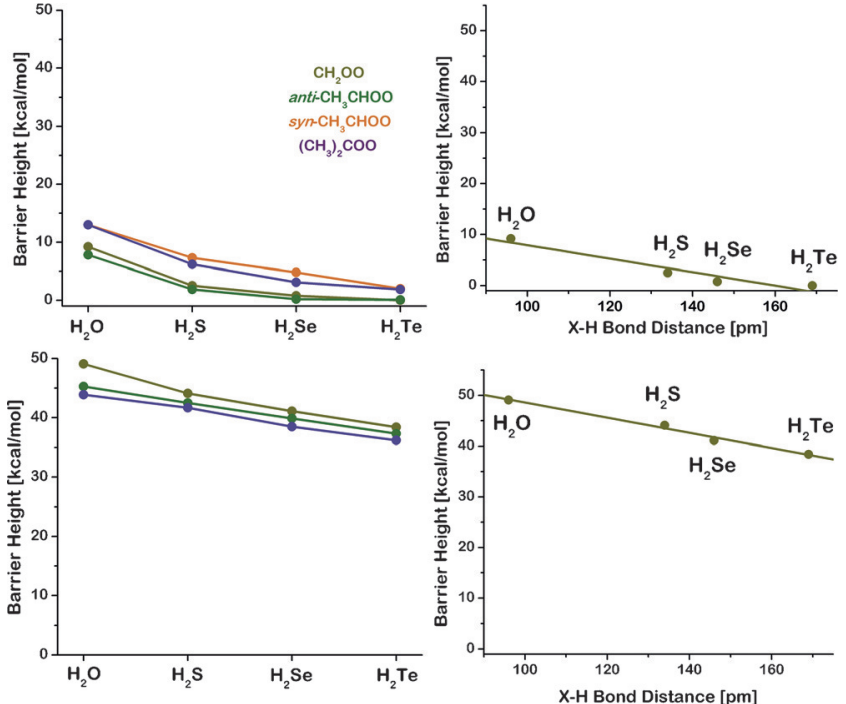

Figure 2. CCSD (T)/aug-cc-pVTZ//M06-2X/aug-cc-pVTZ calculated zero-point-corrected barriers (top panels: addition reactions and bottom panels: elimination reactions) for the reactions between various Criegee intermediates and chalcogen hydrides. The barriers are given in $\mathrm{kcal} \mathrm{mol}^{-1}$ units. The correlations between the calculated barriers for the reactions of the simplest Criegee intermediate, $\mathrm{CH}_{2} \mathrm{OO}$ with chalcogen hydrides and $\mathrm{X}-\mathrm{H}(\mathrm{X}=\mathrm{O}, \mathrm{S}, \mathrm{Se}$, and $\mathrm{Te})$ bond distances are given in right side panels.

chalcogen hydrides with heteroatoms lying in the lower end of the periodic table would react faster with Criegee intermediate.

We then examined the reactions of the next larger Criegee intermediate, $\mathrm{CH}_{3} \mathrm{CHOO}$ with $\mathrm{H}_{2} \mathrm{X}$. There are two conformers possible for $\mathrm{CH}_{3} \mathrm{CHOO}$ : i) anti- $\mathrm{CH}_{3} \mathrm{CHOO}$ and ii) syn- $\mathrm{CH}_{3} \mathrm{CHOO}$. We studied reactions involving both of these conformers. The calculations suggest that the barriers for the anti- $\mathrm{CH}_{3} \mathrm{CHOO}$ reactions are relatively lower than those for the syn- $\mathrm{CH}_{3} \mathrm{CHOO}$ reactions (Figure 2), which is consistent with previous studies ${ }^{[8,15]}$ suggesting that anti$\mathrm{CH}_{3} \mathrm{CHOO}$ is more reactive than syn- $\mathrm{CH}_{3} \mathrm{CHOO}$ towards bimolecular reactions. For the $\mathrm{H}_{2} \mathrm{O}$ or $\mathrm{H}_{2} \mathrm{~S}$ reactions, the addition barrier for the anti- $\mathrm{CH}_{3} \mathrm{CHOO}$ case is about $5.0 \mathrm{kcalmol}^{-1}$ lower than that for the syn- $\mathrm{CH}_{3} \mathrm{CHOO}$ case. More importantly, the calculated barriers for the addition and elimination steps of the anti- and syn- $\mathrm{CH}_{3} \mathrm{CHOO}-\mathrm{H}_{2} \mathrm{X}$ reactions correlate well with the bond length of $\mathrm{X}-\mathrm{H}$ bond of $\mathrm{H}_{2} \mathrm{X}$ (Figures $\mathrm{S} 2$ and $\mathrm{S} 3$ ) or their first $\mathrm{p} K_{\mathrm{a}}$ values. In going from $\mathrm{H}_{2} \mathrm{O} \rightarrow \mathrm{H}_{2} \mathrm{Te}$, the addition barrier for the anti$\mathrm{CH}_{3} \mathrm{CHOO}$ case is lowered by $7.8 \mathrm{kcal} \mathrm{mol}^{-1}$ and the $\mathrm{H}_{2} \mathrm{X}$ addition occurs in a near-barrierless manner for $\mathrm{X}=\mathrm{Se}$ or Te. For the syn- $\mathrm{CH}_{3} \mathrm{CHOO}$ case, the larger barrier lowering of $11.0 \mathrm{kcal} \mathrm{mol}^{-1}$ is observed in moving from $\mathrm{H}_{2} \mathrm{O} \rightarrow \mathrm{H}_{2} \mathrm{Te}$. Since the $\mathrm{H}_{2} \mathrm{X}$ addition to anti or syn- $\mathrm{CH}_{3} \mathrm{CHOO}$ should lead to the same hydroperoxide, $(\mathrm{HX})\left(\mathrm{CH}_{3}\right)(\mathrm{H}) \mathrm{COOH}$, we only examined $\mathrm{H}_{2} \mathrm{O}_{2}$ elimination from the anti- $\mathrm{CH}_{3} \mathrm{CHOO}+\mathrm{H}_{2} \mathrm{X}$ reaction. The barrier for the $\mathrm{H}_{2} \mathrm{O}_{2}$ elimination from the $(\mathrm{HX})\left(\mathrm{CH}_{3}\right)(\mathrm{H}) \mathrm{COOH}$ is lowered from $45.3 \mathrm{kcalmol}^{-1}$ to $37.3 \mathrm{kal} \mathrm{mol}^{-1}$ in going from $\mathrm{H}_{2} \mathrm{O} \rightarrow \mathrm{H}_{2} \mathrm{Te}$, which again inversely correlates with the $\mathrm{X}-\mathrm{H}$ bond strength or directly correlates with first $\mathrm{p} K_{\mathrm{a}}$ value of $\mathrm{H}_{2} \mathrm{X}$. 
The calculated addition and elimination barriers for the reactions of $\left(\mathrm{CH}_{3}\right)_{2} \mathrm{COO}$ with $\mathrm{H}_{2} \mathrm{X}$ also satisfy a correlation with the $\mathrm{X}-\mathrm{H}$ bond length (Figures 2, S2 and S3) or first $\mathrm{p} K_{\mathrm{a}}$ value of $\mathrm{H}_{2} \mathrm{X}$, which is indicative of the fact that the correlation between the Criegee reaction barrier and the nature of $\mathrm{X}$ in $\mathrm{H}_{2} \mathrm{X}$ is a common reactivity trend, and is independent of the structure of the Criegee intermediate involved in the reaction. The comparative analysis suggests that the calculated elimination barriers for the $\left(\mathrm{CH}_{3}\right)_{2} \mathrm{COO}$ reactions are not only lower than those for the syn$\mathrm{CH}_{3} \mathrm{CHOO}$, but are the lowest ones. For example, the elimination barriers for $\mathrm{H}_{2} \mathrm{O}$ and $\mathrm{H}_{2}$ Te reactions are lowered from 49.1 and $38.4 \mathrm{kcalmol}^{-1}$ to 43.9 and $36.2 \mathrm{kcalmol}^{-1}$, respectively, in going from $\mathrm{CH}_{2} \mathrm{OO}$ to $\left(\mathrm{CH}_{3}\right)_{2} \mathrm{COO}$. This is due to the fact that the substitution at the hydroperoxy carbon of $(\mathrm{HX})\left(\mathrm{R}_{1}\right)\left(\mathrm{R}_{2}\right) \mathrm{COOH}$ promotes the $\mathrm{H}_{2} \mathrm{O}_{2}$ elimination, that is, the greater the extent of substitution, the lower would be the elimination barrier.

The correlation between the Criegee reaction barrier and the nature of heteroatom in $\mathrm{H}_{2} \mathrm{X}$ may have important implications for atmospheric and synthetic organic chemistry. For example, thioformaldehyde (HCHS) has been detected in dark clouds, the interstellar clouds ${ }^{[18-20]}$ and circumsteller envelope around an asymptotic giant branch star. ${ }^{[21]}$ Few lines of HCHS have also been identified in the Orion KL nebula ${ }^{[22]}$ and in the atmosphere of the comet Hale-Bopp. ${ }^{[23]}$ The present calculations suggest that HCHS in the atmosphere could be formed in a near-barrierless manner from the reaction between $\mathrm{CH}_{2} \mathrm{OO}$ and $\mathrm{H}_{2} \mathrm{~S}$. This reaction could be feasible in the atmosphere because the estimated $\mathrm{H}_{2} \mathrm{~S}$ concentration in the lower troposphere lies in the 11000 ppt range. Another important implication of our results is for the laboratory synthesis of thioaldehydes. In synthetic organic chemistry, thioaldehydes are used as key building blocks. The Diels-Alder additions of thioaldehydes and thioketones offer useful routes for the incorporation of sulfur heteroatoms into the synthesis of heterocycles such as substituted pyridines, furans, and dihydrothiopyrans or natural products. ${ }^{[24-26]}$ However, experimental detection of simpler aliphatic thioaldehydes such as HCHS has been a significant challenge because it is unstable at room temperature and readily trimerizes to s-trithiane. ${ }^{[27]}$ The findings from this work suggest that if the reaction of the Criegee intermediate and $\mathrm{H}_{2} \mathrm{~S}$ could be performed in the presence of water or a carboxylic acid (Figure 3 and Table S2), thioladehydes would be formed in an extensively hydrogen-bonded complexed state, which is signficantly more stable than their uncomplexed one. Thus, the water or acid-mediated reaction of the Criegee intermediate and $\mathrm{H}_{2} \mathrm{~S}$ could selectively produce thioaldehyde, avoiding any oligomerization. This could prove useful synthetic guidelines for the laboratory synthesis of simpler thioaldehydes that does not require harsh experimental conditions.

In short, high-level quantum-chemical calculations reveal an inverse correlation between the reaction barrier of Criegee intermediates and $\mathrm{H}_{2} \mathrm{X}$ and the bond length of the $\mathrm{X}-\mathrm{H}$ bond in $\mathrm{H}_{2} \mathrm{X}$ or a direct correlation with the first $\mathrm{p} K_{\mathrm{a}}$ value of $\mathrm{H}_{2} \mathrm{X}$. This heteroatom-induced tuning causes an $8-12 \mathrm{kcal} \mathrm{mol}^{-1}$ lowering in the reaction barrier, thus significantly impacting

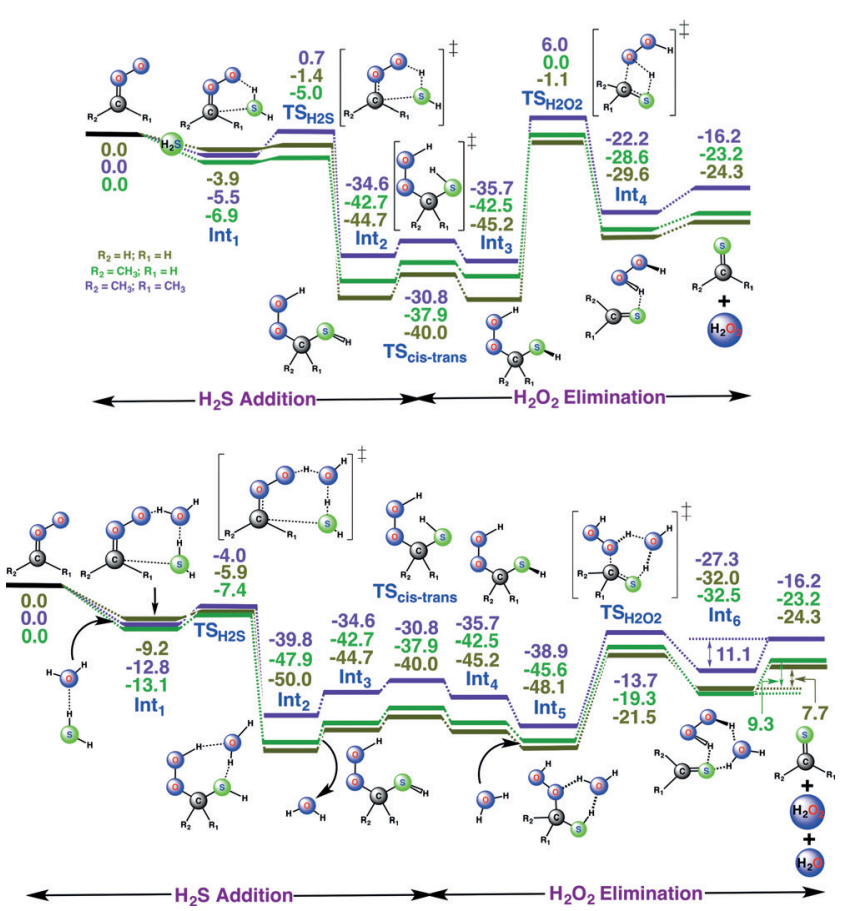

Figure 3. $\operatorname{CCSD}(\mathrm{T}) /$ aug-cc-pVTZ//M06-2X/aug-cc-pVTZ calculated zero-point-corrected reaction profiles for the reactions between various Criegee intermediates and hydrogen sulfide with (bottom panel) and without water catalyst (top panel). The energetics are given in kcal mol ${ }^{-1}$ units.

the overall energetics of the reaction of Criegee intermediates and $\mathrm{H}_{2} \mathrm{X}$. Considering that bimolecular reactions are abundant in atmosphere, the heteratom tuning of the reaction barrier could be a common reactvity determinant of atmospheric addition reactions.

Keywords: atmospheric chemistry - chalcogen hydrides . Criegee intermediates $\cdot$ organocatalysis - water catalysis

How to cite: Angew. Chem. Int. Ed. 2016, 55, 13432-13435 Angew. Chem. 2016, 128, 13630-13633

[1] D. Johnson, G. Marston, Chem. Soc. Rev. 2008, 37, 699-716.

[2] K. E. Leather, M. R. McGillen, M. C. Cooke, S. R. Utembe, A. T. Archibald, M. E. Jenkin, R. G. Derwent, D. E. Shallcross, C. J. Percival, Atmos. Chem. Phys. 2012, 12, 469.

[3] R. L. Mauldin III, T. Berndt, M. Sipil., P. Paasonen, T. Petäjä, S. Kim, T. Kurtén, F. Stratmann, V.-M. Kerminen, M. Kulmala, Nature 2012, 488, 193.

[4] K. J. Heaton, R. L. Sleighter, P. G. Hatcher, W. A. Hall, M. V. Johnston, Environ. Sci. Technol. 2009, 43, 7797.

[5] Y. Ma, R. A. Porter, D. Chappell, A. T. Russell, G. Marston, Phys. Chem. Chem. Phys. 2009, 11, 4184.

[6] C. A. Taatjes, O. Welz, A. J. Eskola, J. D. Savee, D. L. Osborn, E. P. F. Lee, J. M. Dyke, D. W. K. Mok, D. E. Shallcross, C. J. Percival, Phys. Chem. Chem. Phys. 2012, 14, 10391.

[7] O. Welz, J. D. Savee, D. L. Osborn, S. S. Vasu, C. J. Percival, D. E. Shallcross, C. A. Taatjes, Science 2012, 335, 204.

[8] C. A. Taatjes, O. Welz, A. J. Eskola, J. D. Savee, A. M. Scheer, D. E. Shallcross, B. Rotavera, E. P. F. Lee, J. M. Dyke, D. K. W. Mok, D. L. Osborn, C. J. Percival, Science 2013, 340, 177.

[9] L. Vereecken, Science 2013, 340, 154-155. 
[10] J. A. Ragan, D. J. am Ende, S. J. Brenek, S. A. Eisenbreis, R. A. Singer, D. L. Tickner, J. J. Teixeira, B. C. Vanderplas, N. Weston, Org. Process Res. Dev. 2003, 7, 155-160.

[11] R. H. Callighan, M. H. Wilt, J. Org. Chem. 1961, 26, 4912-4914.

[12] S. G. Van Ornum, R. M. Champeau, R. Pariza, Chem. Rev. 2006, 106, 2990-3001.

[13] H. Leisch, K. Morley, P. Lau, Chem. Rev. 2011, 111, 4165-4222.

[14] A. Baeyer, V. Villiger, Ber. Dtsch. Chem. Ges. 1899, 32, $3625-$ 3633.

[15] J. M. Anglada, J. Gonzalez, M. Torrent-Sucarrat, Phys. Chem. Chem. Phys. 2011, 13, 13034.

[16] D. A. Johnson, Some Thermodynamic Aspects of Inorganic Chemistry, 2nd ed., University Press, Cambridge, 1982, p. 207.

[17] R. P. Bell, The proton in Chemistry, 2nd ed., Cornell University Press, Ithaca, 1973.

[18] N. J. Evans, C. H. Townes, H. F. Weaver, D. R. Williams, Science 1970, 169, 680-681.

[19] M. W. Sinclair, N. Fourikis, J. C. Ribes, B. J. Robinson, R. D. Brown, P. D. Godfrey, Aust. J. Phys. 1973, 26, 85-91.
[20] Y. C. Minh, W. M. Irvine, M. K. Brewer, Astron. Astrophys. 1991, $244,181-189$

[21] M. Agúndez, J. P. Fonfría, J. Cernicharo, J. R. Pardo, M. Guélin, Astron. Astrophys. 2008, 479, 493-501.

[22] C. Comito, P. Schilke, T. G. Phillips, D. C. Lis, F. Motte, D. Mehringer, Astrophys. J. Suppl. Ser. 2005, 156, 127-167.

[23] L. M. Woodney, M. F. A'Hearn, J. McMullin, N. Samarasinha, Earth Moon Planets 1997, 78, 69-70.

[24] E. Vedejs, T. H. Eberlein, D. L. Varie, J. Am. Chem. Soc. 1982, $104,1445-1447$.

[25] R. Okazaki in Organsulfur Chemistry (Ed.: P. D. Page), Academic Press, London, 1995, p. 226.

[26] F. Duus, Comprehensive Organic Chemistry, Vol. 3 (Eds.: D. H. R. Barton, W. D. Ollis), Pergamon, Oxford, 1979, p. 373. [27] R. H. Judge, G. W. King, Can. J. Phys. 1975, 53, 1927-1928.

Received: May 17, 2016

Published online: September 28, 2016 